\title{
Dynamic model for a dense medium drum separator in coal beneficiation
}

\author{
E.J. Meyer ${ }^{\mathrm{a}, \mathrm{b}}$, I.K. Craig ${ }^{\mathrm{b}, *}$ \\ ${ }^{a}$ Snr Solution Architect, MES E Plant - Business Solution Provision, Exxaro Resources, PO Box 9229, Pretoria 0001, South Africa \\ ${ }^{b}$ Department of Electrical, Electronic and Computer Engineering, University of Pretoria, Pretoria 0002, South Africa
}

\begin{abstract}
Dense medium drum (DMD) separators are unit processes that are typically used to beneficiate coal, iron ore and other minerals by making use of density separation. Some coal dense medium separation plants typically include a DMD separator. The operational management of this unit process is often limited to localised control of medium density and feed mass flow rate. Dynamic models for coal dense medium separation have been developed by the authors with the intention of using them for dynamic control.

A suitable dynamic model for a DMD separator could not been found in the available literature. This paper shows how the dynamic model for a dense medium cyclone has been applied to a DMD separator. The model parameters were determined and the performance of the model is evaluated using actual plant data from a Wemco drum. An additional aspect employing coal washability and drum partitioning behaviour is applied to estimate the grade of the product for model grade simulation and validation.
\end{abstract}

Keywords: dense medium drum, dense medium separation, coal beneficiation, dynamic modelling, steady-state modelling, process control, simulation

\section{Introduction}

This work is based on Meyer and Craig (2010) which details the development of dynamic models for a dense medium separation process in coal processing. These dynamic models were developed using first principles and include models for screening, medium make-up and dense medium separation through cyclones. As far as the authors are aware, a dynamic model for a dense medium drum (DMD) separator is not available in the open literature. Since a drum separator is an integral unit process required in coal beneficiation (King, 1999) it is necessary that a dynamic model be generated for this unit process such that a process controller can be implemented.

The dynamic model for the drum separator is developed from first principles where the conservation of mass and mass of components are used (Stephanopoulos, 1984). The dense medium cyclone (DMC) dynamic model of Meyer and Craig (2010) is applied to the drum separator. However, certain assumptions are modified to cater for the different mechanisms of separation between a cyclone model and a drum separator model. The validation of the dynamic drum separator model requires a steady-state model, similar to that of Meyer and Craig (2011).

This paper initially describes the metallurgy of minerals processing regarding the operation of DMD separators in Section 2. It highlights the process models available for drum separation. A high level description of the process to be used to obtain the dynamic model of the drum separator is also given. A detailed description of how the dynamic drum separator model is determined is given in Section 3. The simulation results are shown in Section 4, and detail the throughput, steady-state parition curve and grade output. A conclusion and summary of the paper is presented in Section 5.

\footnotetext{
${ }^{*}$ Corresponding author. Tel.: +27 12420 2172; fax: +27 123625000

Email address: ian.craig@up. ac.za (I.K. Craig)
} 


\section{Dense medium drum process and process model}

The process flow diagram in Figure 1 shows a typical DMD circuit which is normally used for separation of large particle sizes ( $+15 \mathrm{~mm}$ to $-100 \mathrm{~mm}$ ) (Hayes, 2003). A magnetite medium ferrofluid is used to facilitate the separation of the coal from discard through density separation. The medium is circulated in a closed circuit and recovered by making use of a magnetic separator. The medium is usually collected in a sump and a density controller is used to correct the density of the medium that is added to the crushed ore. Screening is used to classify the ore before the density separation stage such that smaller sized coal feed can be separated using a DMC circuit.

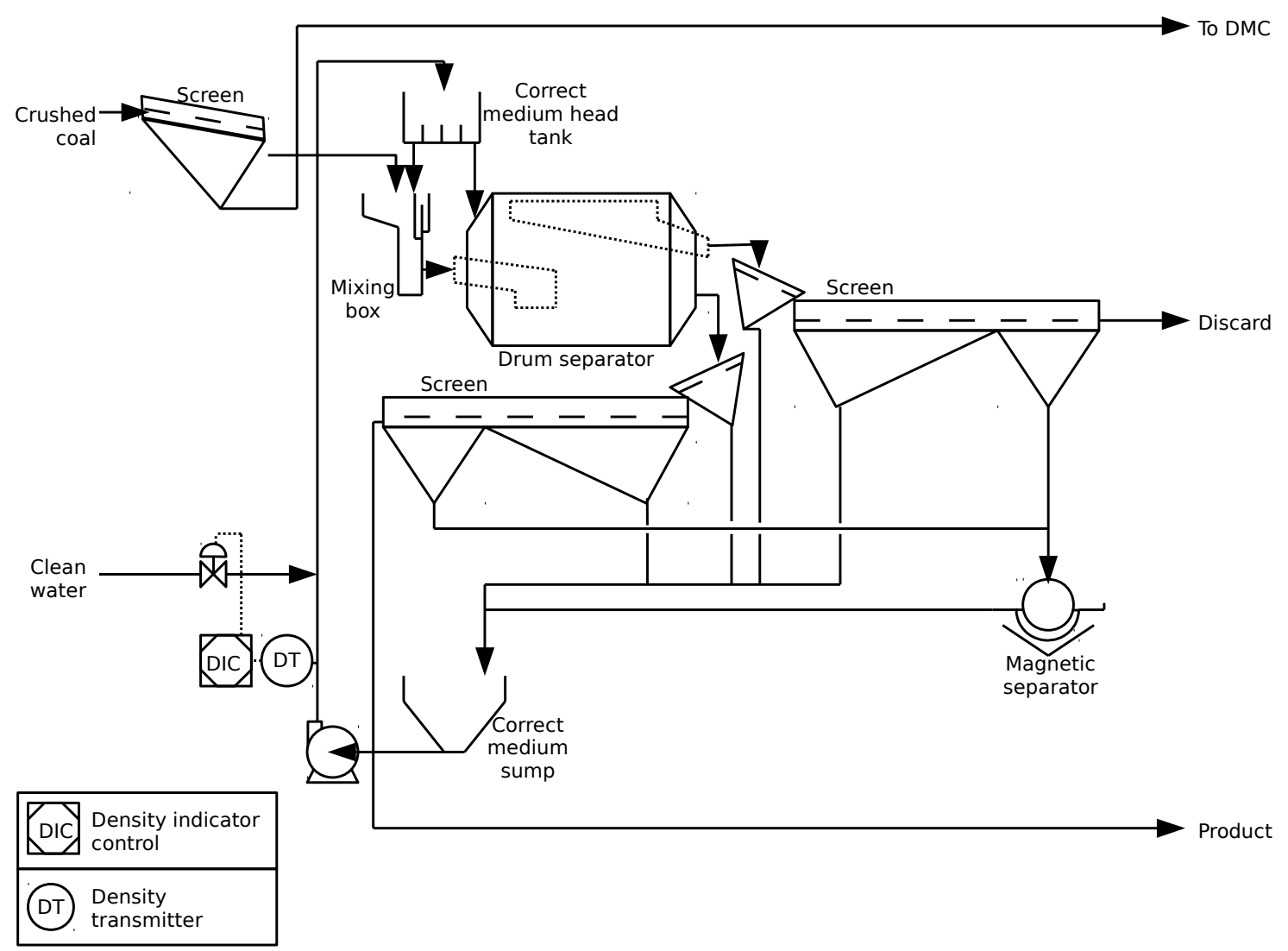

Figure 1: Dense medium drum circuit (Adapted from England et al. (2002)).

Drum separators operate on the principle of float and sink separation where particles of different densities to the medium can either float or sink in the medium due to gravity. Coal feed is mixed with the medium and processed through a relatively static container. England et al. (2002) describe two main horizontal drum separators used in industry being the Wemco or Teska drum. Although the principle of operation is similar for each type of drum separator, this paper will apply the dynamic model to a Wemco drum as this is the industrial unit that was available for the research.

The Wemco drum (Figure 2) consists of a steel shell with a tyre and collar construction (Wilkes, 2006) where the drum operates in a longitudinal position. The drum shell rotates using a drive chain. During rotation, medium is added to the feed chute and sinks launder. Sinks are collected by sink lifters and discharged into the sinks launder. Floats exit through the lower exit of the drum.

\subsection{Partition curve}

Napier-Munn (1991) referenced a process model for a DMD separator. Sedimentation theory (Scott and Lyman, 1987) was used to detail the separation cutpoint (relative density where a particle has an equal chance of reporting to 


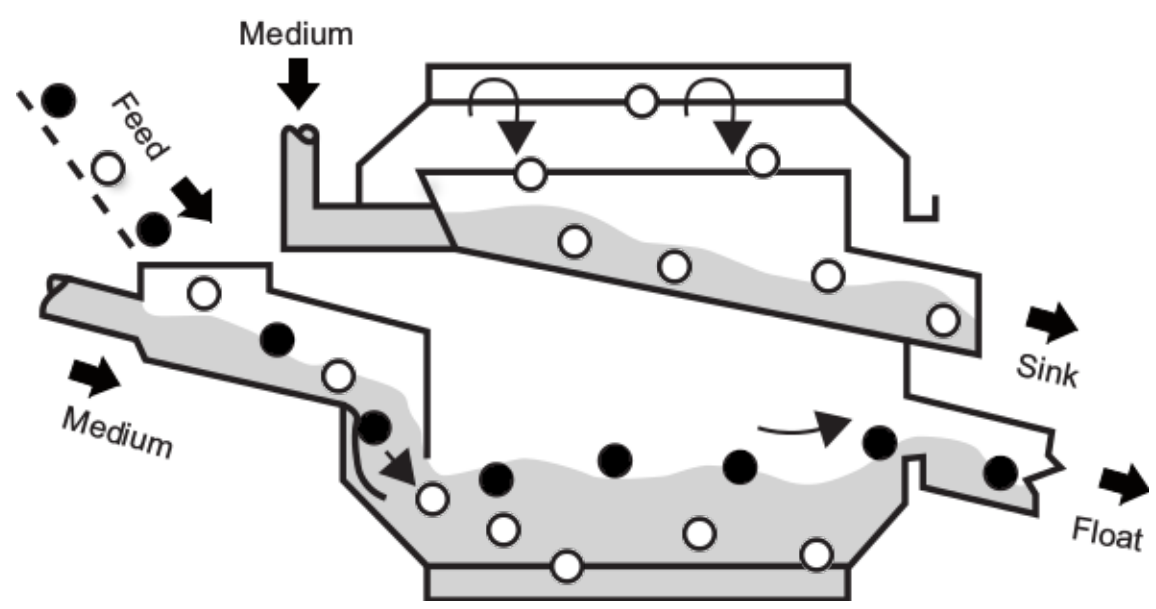

Figure 2: The Wemco drum (Wilkes, 2006). Black particles represent coal while white particles represent discard.

the float or sink). The partition factor (Baguley and Napier-Munn, 1996) for the drum separator is described as,

$$
Y=\left[1-\left(v_{100}-v_{t}\right)^{2}\right]^{\left(\frac{A_{d r m}}{d^{2}+B_{d r m}}\right)},
$$

where $v_{100}$ is the terminal velocity, which allows for sinks to be recovered $100 \%, v_{t}$ is the terminal velocity of the particle and $A_{d r m}$ and $B_{d r m}$ are constants that need to be estimated. The particle size is represented by $d$.

Using the terminal speed $v_{t}=\sqrt{\frac{2 F_{g}}{C \rho_{d, i, m e d} A}}$ from Halliday et al. (2001) where $F_{g}$ is the downward gravitational force on the ore particle, $C$ is the drag coefficient for the ore particle, $\rho_{d, i, m e d}$ is the medium density displacing the ore particle mass per volume and $A$ is the effective cross-sectional area of the ore particle, the steady-state partition factor (equation 1) can be made a function of medium density $\left(\rho_{d, i, m e d}\right)$. By assigning parameters $p_{1}=v_{100}, p_{2}=\frac{2 F_{g}}{C A}$ and $p_{3}=\frac{A_{d r m}}{d^{2}+B_{d r m}}$, a parametric equation for the partition factor can be derived as follows,

$$
Y\left(\rho_{d, i, \text { med }}\right)=\left[1-\left(p_{1}-\sqrt{\frac{p_{2}}{\rho_{d, i, m e d}}}\right)^{2}\right]^{p_{3}} .
$$

Similar results could possibly be obtained by using the terminal velocity correlation published by Concha and Almendra (1979), with an adjustment for shape factor.

Figure 3 shows an example of a typical partition curve or efficiency curve taken from England et al. (2002). The ideal partition curve is a step function allowing for perfect separation. However, since unit processes such as the DMD do not separate perfectly, the real efficiency curve is typically an S-shaped curve of a cumulative probability distribution. In this example the probability of particles reporting as floats is shown. The location of the curve is described by the separation cutpoint (the specific relative density where a particle can have an equal chance of reporting to a float or sink) and is described as $\rho_{50}$. The écart probable moyen (EPM) is an empirical measure of inefficiency. This separation efficiency is typically calculated as follows:

$$
\mathrm{EPM}=\frac{\rho_{25}-\rho_{75}}{2},
$$

where $\rho_{25}$ is the specific gravity (SG) at $25 \%$ and $\rho_{75}$ is the SG at $75 \%$ (Terra, 1938). Since this paper describes a dynamic model of a DMD while the partition curve is a steady-state process model, the DMD dynamic model is reduced to a steady-state model in Section 4.2 to show the similarity to a typical partition curve.

\subsection{Washability curve}

Another process model (Wills and Napier-Munn, 2006) used to determine the required density for coal separation and the expected yield of coal of the required grade is a washability curve (Reinhardt, 1911). The quality of coal is 


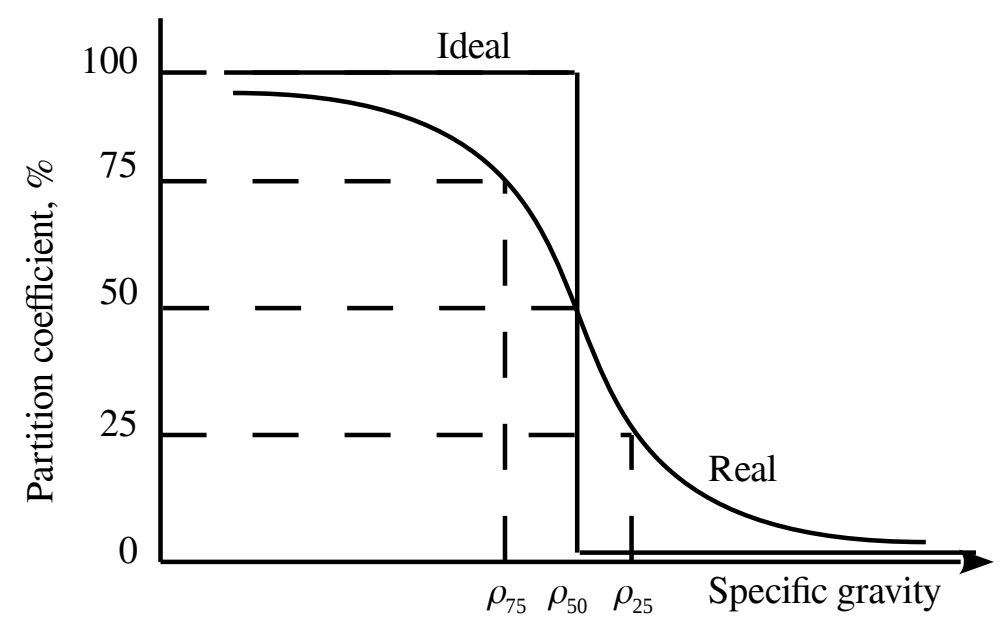

Figure 3: Example of a partition curve (England et al., 2002).

usually measured as ash content which is the amount of incombustible material in the coal. Using float-sink analysis, it is possible to generate a washability curve describing the characteristics of the coal at different relative density (RD) fractions (England et al., 2002). An example of the coal washability curve describing the coal beneficiated by an industrial DMD used for this paper is given in Figure 4. Bowen and Jowett (1986) describe various mathematical

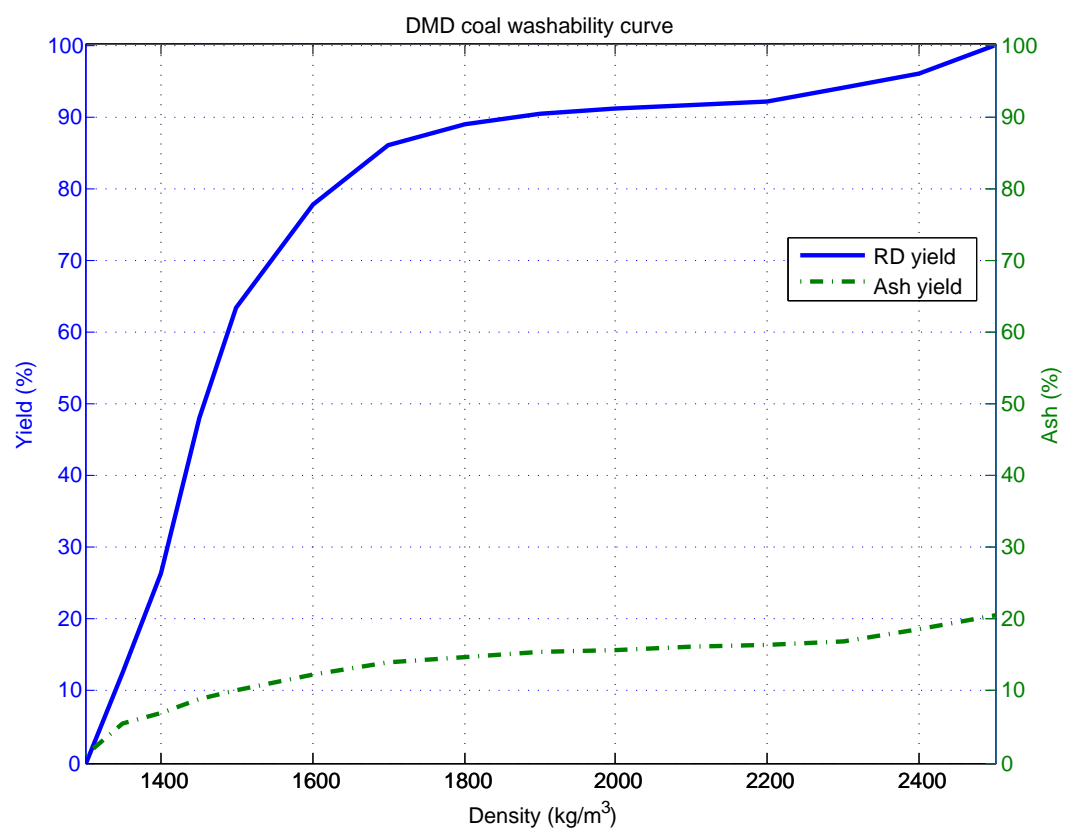

Figure 4: DMD coal plant actual washability curve. Washability curve data is based on bench 11 from the Grootegeluk formation (Faure et al., 1996).

models for a coal cleaning system to be used for computational calculations for coal washability. The M-curve is a simple curve that can generally fit a conic section equation which typically represents a washability curve. Bowen and Jowett (1986) show a general conic equation that will fit almost any M-curve plot as,

$$
b_{0}+b_{1} x_{d, f, a s h}+b_{2} y+b_{3} x_{d, f, a s h}^{2}+b_{4} y^{2}+b_{5} x_{d, f, a s h} y=0,
$$


where $x_{f, a s h}$ represents the ash product or float percentage, $y$ represents the yield and the model parameters are given as $b_{0}, b_{1}, b_{2}, b_{3}, b_{4}$ and $b_{5}$.

By fitting equation 4 to the measured washability data from Figure 4, Figure 5 was generated.

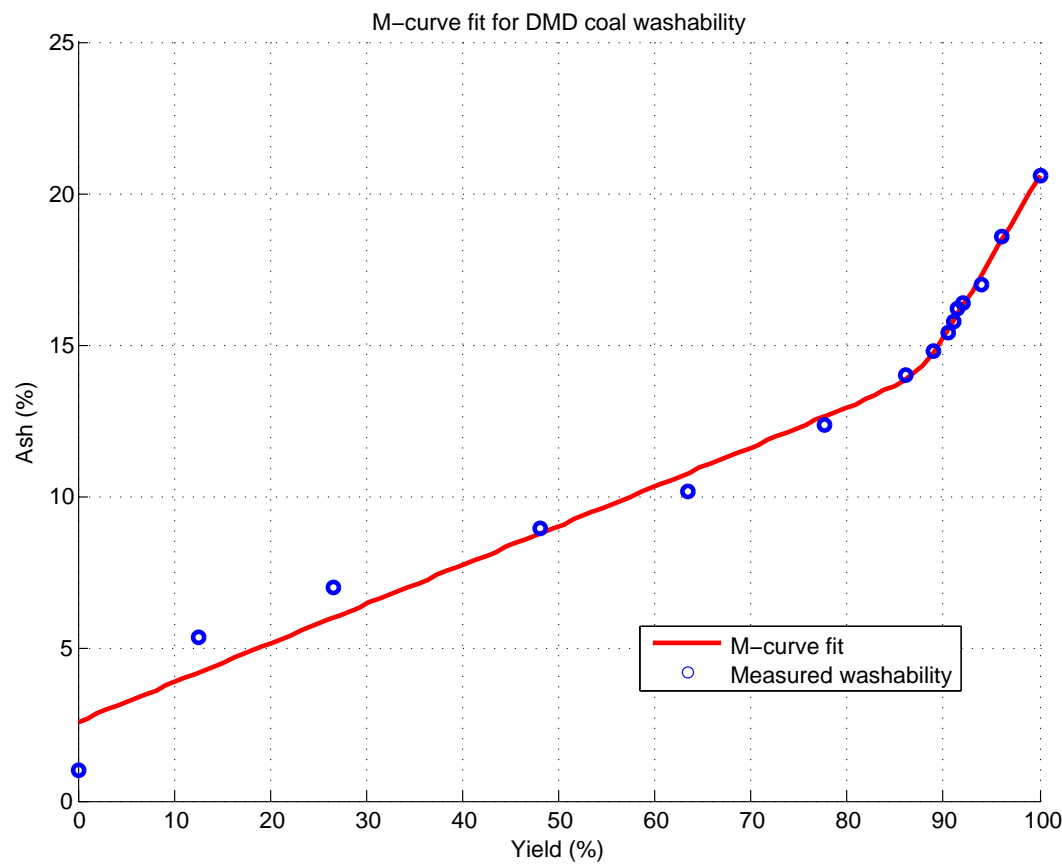

Figure 5: M-curve of the coal washability for the DMD process.

Table 1 shows a summary of the parameters for M-curve fit. This result shows that the DMD product ash content can be expressed as a function of yield.

Table 1: M-curve model parameters.

\begin{tabular}{ll}
\hline M-curve parameter & Curve fit parameter results \\
\hline \hline$b_{0}$ & -0.19 \\
$b_{1}$ & 6.91 \\
$b_{2}$ & -0.65 \\
$b_{3}$ & 21.83 \\
$b_{4}$ & 1.54 \\
$b_{5}$ & -14.78 \\
\hline \hline
\end{tabular}

The M-curve [developed by Mayer (1950)] parametric equation will be used in this paper to estimate the product ash contents in order to verify the grade as estimated by the dynamic model. The feed ash content $\left(x_{d, i, a s h}\right)$ is calculated by reconstituting the feed as follows,

$$
x_{d, i, a s h}=\frac{W_{d, f} x_{d, f, a s h}}{W_{d, i} Y\left(\rho_{d, i, m e d}\right)},
$$

where $W_{d, f}$ is the product mass rate, $W_{d, i}$ is the feed mass rate, $x_{d, f, a s h}$ is the float or product ash contents and $Y\left(\rho_{d, i, m e d}\right)$ is the partition factor described by equation 2 .

\section{Dynamic model development and system identification}

Although the process models indicated above are useful for process engineering, they are generally not applicable on their own for process control as they do not incorporate the time evolution of process variables. Since, as far as 
the authors are aware, no dynamic model of a drum separator is available in literature, one is developed using the first principle model in Meyer and Craig (2010).

The dynamic model of the drum separator focuses on throughput equations by making use of the conservation of overall mass. Conservation of mass of components can be used to model the grade (i.e. ash percentage) of the drum coal product. A model representation of the drum separator can be found in Figure 6 while associated variables describing the model are given in Tables 2 and 3.

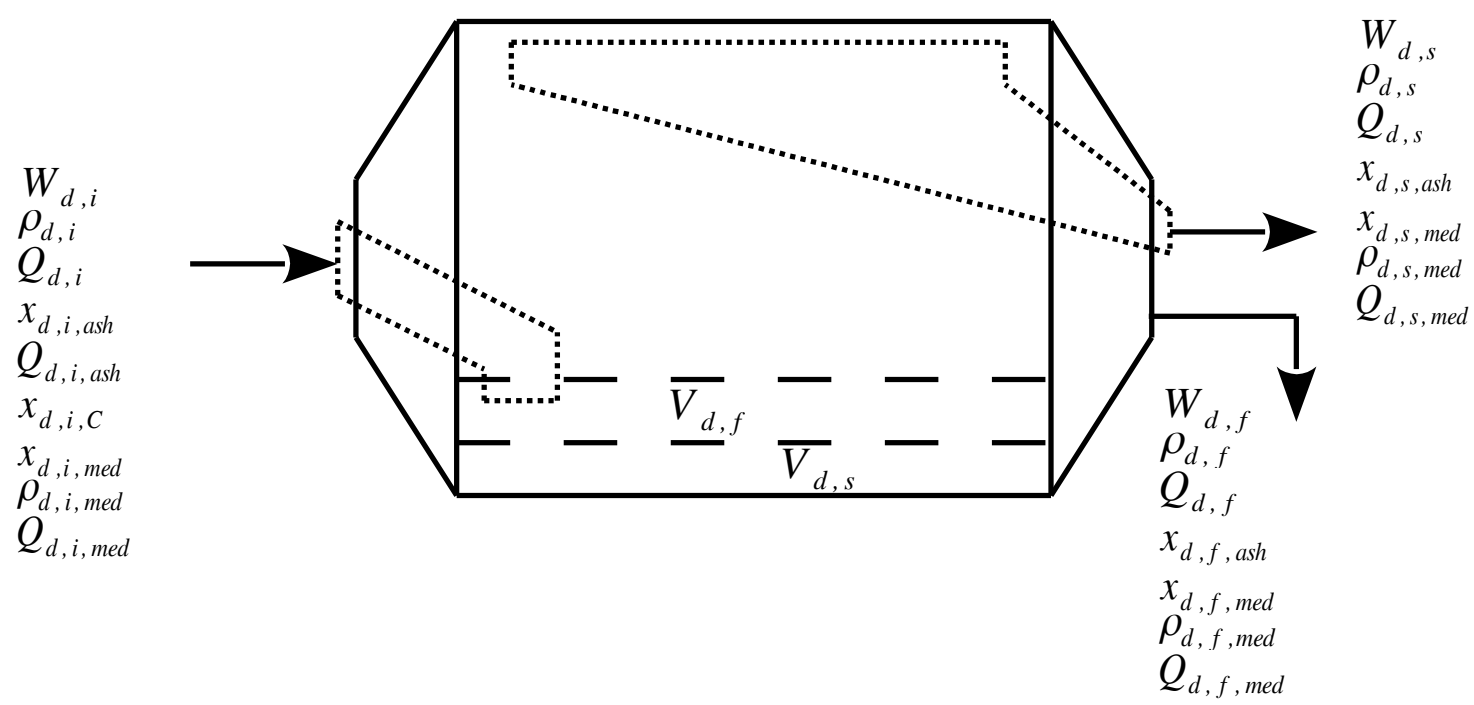

Figure 6: Model representation of a DMD.

Table 2: Drum input variables

\begin{tabular}{ll}
\hline Variable & Description \\
\hline$W_{d, i}$ & Mass feed rate of the feed mix $(\mathrm{kg} / \mathrm{s})$ \\
$\rho_{d, i}$ & Density of the feed mix $\left(\mathrm{kg} / \mathrm{m}^{3}\right)$ \\
$V_{d}=V_{d, f}+V_{d, s}$ & Volume of the material within the drum $\left(\mathrm{m}^{3}\right)$ \\
$x_{d, i, a s h}, x_{d, i, C}$ & Percentage ash and fixed carbon in the feed mix \\
$Q_{d, i, a s h}$ & Volumetric flow rate of the ash content in the feed $\operatorname{mix}\left(\mathrm{m}^{3} / \mathrm{s}\right)$ \\
$x_{d, i, m e d}$ & Percentage magnetite medium in the feed mix \\
$\rho_{d, i, m e d}$ & Density of the magnetite medium in the feed mix $\left(\mathrm{kg} / \mathrm{m}^{3}\right)$ \\
$Q_{d, i, \text { med }}$ & Volumetric flow rate of the magnetite medium in the feed mix $\left(\mathrm{m}^{3} / \mathrm{s}\right)$ \\
\hline
\end{tabular}

The following is a list of assumptions that were made:

- The volume of the mix in the drum $\left(V_{d}\right)$ is constant.

- The volume of the floats $\left(V_{d, f}\right)$ and sinks $\left(V_{d, s}\right)$ mix in the drum is split at a constant ratio $\alpha_{d}$.

- The volumetric flow rates of the feed $\left(Q_{d, i}\right)$, floats $\left(Q_{d, f}\right)$ and sinks $\left(Q_{d, s}\right)$ are constant before and after a step is introduced in the medium density $\left(\rho_{d, i, m e d}\right)$ or feed rate of the ore $\left(W_{d, i}\right)$.

- The volumetric flow rates of the floats $\left(Q_{d, f}\right)$ and sinks $\left(Q_{d, s}\right)$ are split at a constant ratio $\alpha$.

- Only ash $\left(x_{d, i, a s h}\right)$, medium $\left(x_{d, i, m e d}\right)$ and fixed carbon $\left(x_{d, i, C}\right)$ components will be considered for the conservation of mass of components in the feed (i.e. $\left.x_{d, i, a s h}+x_{d, i, m e d}+x_{d, i, C}=1\right)$.

- Medium and ash components are considered for the conservation of mass of components in the floats $\left(x_{d, f, m e d}\right.$, $\left.x_{d, f, a s h}\right)$ and sinks $\left(x_{d, s, m e d}, x_{d, s, a s h}\right)$. 
Table 3: Drum output variables

\begin{tabular}{ll}
\hline Variable & Description \\
\hline$W_{d, f}$ & Mass flow rate of the floats $(\mathrm{kg} / \mathrm{s})$ \\
$\rho_{d, f}$ & Density of the floats $\left(\mathrm{kg} / \mathrm{m}^{3}\right)$ \\
$Q_{d, f}$ & Volumetric flow rate of the floats $\left(\mathrm{m}^{3} / \mathrm{s}\right)$ \\
$V_{d, f}$ & Volume split of the floats within the drum $\left(\mathrm{m}^{3}\right)$ \\
$x_{d, f, a s h}$ & Percentage ash content in the floats \\
$x_{d, f, \text { med }}$ & Percentage magnetite medium in the floats \\
$\rho_{d, f, \text { med }}$ & Density of the magnetite medium in the floats $\left(\mathrm{kg} / \mathrm{m}^{3}\right)$ \\
$\left.Q_{d, f, \text { med }}\right)$ & Volumetric flow rate of the magnetite medium in the floats $\left(\mathrm{m}^{3} / \mathrm{s}\right)$ \\
$W_{d, s}$ & Mass flow rate of the sinks $(\mathrm{kg} / \mathrm{s})$ \\
$\rho_{d, s}$ & Density of the sinks $\left(\mathrm{kg} / \mathrm{m}^{3}\right)$ \\
$Q_{d, s}$ & Volumetric flow rate of the sinks $\left(\mathrm{m}^{3} / \mathrm{s}\right)$ \\
$V_{d, s}$ & Volume split of the sinks within the drum $\left(\mathrm{m}^{3}\right)$ \\
$x_{d, s, a s h}$ & Percentage ash content in the sinks \\
$x_{d, s, \text { med }}$ & Percentage magnetite medium in the sinks \\
$\rho_{d, s, \text { med }}$ & Density of the magnetite medium in the sinks $\left(\mathrm{kg} / \mathrm{m}^{3}\right)$ \\
$Q_{d, s, \text { med }}$ & Volumetric flow rate of the magnetite medium in the $\operatorname{sinks~}\left(\mathrm{m}^{3} / \mathrm{s}\right)$ \\
\hline
\end{tabular}

- The rates of change in mass for the floats $\left(\frac{d W_{d, f}}{d t}\right)$ and sinks $\left(\frac{d W_{d, s}}{d t}\right)$ are proportional to the difference in their densities $\left(\rho_{d, f}\right.$ and $\left.\rho_{d, s}\right)$ to the magnetite medium density $\left(\rho_{d, i, m e d}\right)$, the acceleration due to gravity $\left(g=9.81 \mathrm{~kg} / \mathrm{s}^{2}\right)$ and the percentage of either ash or carbon in the feed $\left(x_{d, i, a s h}\right.$ or $\left.x_{d, i, C}\right)$.

In order to simplify the model, it is assumed that the volumetric flow is at steady state (i.e. $Q_{d, i}=Q_{d, f}+Q_{d, s}$ ) and that the floats and sinks are volumetrically split by a proportion $\alpha$. This means that $Q_{d, f}=\alpha Q_{d, s}$ (i.e. $Q_{d, f}=\frac{\alpha Q_{d, i}}{1+\alpha}$ and $\left.Q_{d, s}=\frac{Q_{d, i}}{1+\alpha}\right)$. Similarly, it is assumed that the drum material volume $V_{d}$ is separated according to the same split proportion $\alpha$ as in the volumetric feed flow (i.e. $V_{d, f}=\frac{\alpha V_{d}}{1+\alpha}$ and $V_{d, s}=\frac{V_{d}}{1+\alpha}$ ). By using the overall conservation of mass the following relationship describing the drum can be developed:

$$
V_{d, f} \frac{d \rho_{d, f}}{d t}+V_{d, s} \frac{d \rho_{d, s}}{d t}=W_{d, i}-Q_{d, f} \rho_{d, f}-Q_{d, s} \rho_{d, s}
$$

Gravity separation within the drum can be used to model the effects of the dynamics of the density response for the drum. The gravitational force $(g)$ indicates that the rates of change in mass for the floats and sinks are proportional to their differences in densities to the medium density. An additional factor was incorporated into the dynamic relationship allowing for the difference in ore density $\left[\rho_{d, i, o r e}=W_{d, i}\left(1-x_{d, i, m e d}\right) /\left(Q_{d, i}-Q_{d, i, m e d}\right)\right]$ to medium density $\left(\rho_{d, i, m e d}\right)$ to facilitate further separation. The percentage of ash or carbon in the feed will also influence the dynamics of the drum. Proportionality constants for floats $\left(K_{d, f}\right)$ and sinks $\left(K_{d, s}\right)$ are used to relate the rates of change of density in floats $\left(\frac{d \rho_{d, f}}{d t}\right)$ and sinks $\left(\frac{d \rho_{d, s}}{d t}\right)$ to these factors and yields the following relationships:

$$
\begin{aligned}
V_{d, f} \frac{d \rho_{d, f}}{d t} & =K_{d, f}\left(\rho_{d, i, \text { ore }}-\rho_{d, i, m e d}\right)\left(\rho_{d, i, m e d}-\rho_{d, f}\right) x_{d, i, C} \\
V_{d, s} \frac{d \rho_{d, s}}{d t} & =K_{d, s}\left(\rho_{d, i, m e d}-\rho_{d, i, \text { ore }}\right)\left(\rho_{d, i, \text { med }}-\rho_{d, s}\right) x_{d, i, a s h} .
\end{aligned}
$$

By combining equation 6 with equations 7 and 8, the floats and sinks density transfer functions for the drum separator can be developed.

Similarly, the conservation of mass of the medium component of the feed material can be determined. This results in the following dynamic mass balance for the medium component,

$$
\begin{gathered}
V_{d, f} \rho_{d, f} \frac{d x_{d, f, \text { med }}}{d t}+V_{d, f} x_{d, f, \text { med }} \frac{d \rho_{d, f}}{d t}+ \\
V_{d, s} \rho_{d, s} \frac{d x_{d, s, \text { med }}}{d t}+V_{d, s} x_{d, s, \text { med }} \frac{d \rho_{d, s}}{d t} \\
=W_{d, i} x_{d, i, \text { med }}-Q_{d, f} \rho_{d, f} x_{d, f, \text { med }}-Q_{d, s} \rho_{d, s} x_{d, s, \text { med }} .
\end{gathered}
$$


To develop solutions for the rates of change in the medium component percentages, some assumptions have to be made. The rates of change in the medium component percentages for the floats and sinks are assumed to be proportional to the difference $\left(\Delta_{\rho_{d, \text { med }}}\right)$ in their feed component density $\left(\rho_{d, i, \text { med }}\right)$ with either the float $\left(\rho_{d, f, \text { med }}\right)$ or sink $\left(\rho_{d, s, m e d}\right)$ medium density. It is also assumed that the rates of change in component percentages are proportional to their acceleration due to gravity $(g)$ and inversely proportional to the average particle size of the ore $(d)$. These factors are taken into consideration by the proportionality constants in the medium floats $\left(K_{d, f, m e d}\right)$ and sinks $\left(K_{d, s, m e d}\right)$. The following relationships for rates of change in medium components can therefore be determined as:

$$
\begin{aligned}
& \frac{d x_{d, f, \text { med }}}{d t}=K_{d, f, \text { med }}\left(-\Delta_{\rho_{d, \text { med }}}\right)\left(x_{d, i, \text { med }}-x_{d, f, \text { med }}\right), \\
& \frac{d x_{d, s, \text { med }}}{d t}=K_{d, s, \text { med }}\left(\Delta_{\rho_{d, \text { med }}}\right)\left(x_{d, i, \text { med }}-x_{d, s, \text { med }}\right) .
\end{aligned}
$$

The dynamic mass balance for the ash component can be determined similarly to the medium component by replacing subscript med with $a s h$. The proportionality constant $\left(\Delta_{\rho_{d, \text { med }}}\right)$ must be replaced by the difference in ash density $\left(\rho_{d, i, a s h}\right)$ to medium density $\left(\rho_{d, i, m e d}\right)$. By using the equations in this section, a non-linear model of the drum separator can be derived.

The system identification process by Ljung (1987) is used to determine the unknown dynamic model parameters of the drum separator model. The newly developed dynamic model is validated using actual plant data from a Wemco drum.

The Wemco drum model was identified using input-output data consisting of three hours of actual production data, sampled once every second. The input data is the drum ore feed rate $W_{d, i, \text { ore }}$ and medium density $\left(\rho_{d, i, m e d}\right)$ and the output data is the float and sink mass rates $\left(W_{d, f}\right.$ and $\left.W_{d, s}\right)$. The proportionality constant $(\alpha)$, proportionality constants for the floats $\left(K_{d, f}\right)$, sinks $\left(K_{d, s}\right)$, medium floats $\left(K_{d, f, m e d}\right)$, medium sinks $\left(K_{d, s, m e d}\right)$, ash floats $\left(K_{d, f, a s h}\right)$, ash sinks $\left(K_{d, s, a s h}\right)$, drum material volumetric flow rate $\left(Q_{d, i}\right)$, medium-to-feed volumetric ratio $\left(Q_{d, i, m e d} / Q_{d, i}\right)$, ash-to-feed ore volumetric ratio $\left[Q_{d, i, a s h} /\left(Q_{d, i}-Q_{d, i, m e d}\right)\right]$ and difference in medium density between the feed with either the floats or $\operatorname{sinks}\left(\Delta_{\rho_{d, \text { med }}}=\rho_{d, i, \text { med }}-\rho_{d, f, \text { med }}=\rho_{d, s, \text { med }}-\rho_{d, i, \text { med }}\right)$ were identified using $66 \%$ of the total input-output data. An ash feed percentage of $28 \%$ and carbon content of $67 \%$ was assumed based on the washability data available.

Table 4 indicates the parameters that were estimated using actual DMD input-output data. Residence time is typically the time it takes for material to be processed through a unit operation while operating at steady-state conditions. The residence time in this model is therefore associated with the volume $\left(V_{d}\right)$ and flow rate $\left(Q_{d, i}\right)$ which are model parameters that require estimation. 
Table 4: Model parameters determined from input-output data.

\begin{tabular}{|c|c|c|}
\hline Parameter & Value & Description \\
\hline$\alpha$ & 0.868 & Float and sink proportionality constant \\
\hline$K_{d, f}$ & $3.558 \mathrm{e}-08$ & $\begin{array}{l}\text { Proportionality constant for the floats } \\
{\left[\mathrm{m}^{6} /(\mathrm{kg} . \mathrm{s})\right]}\end{array}$ \\
\hline$K_{d, s}$ & $3.076 \mathrm{e}-12$ & $\begin{array}{l}\text { Proportionality constant for the sinks } \\
{\left[\mathrm{m}^{6} /(\mathrm{kg} . \mathrm{s})\right]}\end{array}$ \\
\hline$K_{d, f, \text { med }}$ & $6.533 \mathrm{e}-08$ & $\begin{array}{l}\text { Proportionality constant for the magnetite } \\
\text { medium floats }\left[\mathrm{m}^{3} /(\mathrm{kg} . \mathrm{s})\right]\end{array}$ \\
\hline$K_{d, s, \text { med }}$ & $3.955 \mathrm{e}-14$ & $\begin{array}{l}\text { Proportionality constant for the magnetite } \\
\text { medium sinks }\left[\mathrm{m}^{3} /(\mathrm{kg} . \mathrm{s})\right]\end{array}$ \\
\hline$K_{d, f, a s h}$ & $-1.057 \mathrm{e}-07$ & $\begin{array}{l}\text { Proportionality constant for the floats ash } \\
{\left[\mathrm{m}^{3} /(\mathrm{kg} . \mathrm{s})\right]}\end{array}$ \\
\hline$K_{d, s, a s h}$ & $1.215 \mathrm{e}-08$ & $\begin{array}{l}\text { Proportionality constant for the sinks ash } \\
{\left[\mathrm{m}^{3} /(\mathrm{kg} . \mathrm{s})\right]}\end{array}$ \\
\hline$Q_{d, i}$ & 0.294 & Volumetric flow rate of the feed $\operatorname{mix}\left(\mathrm{m}^{3} / \mathrm{s}\right)$ \\
\hline$V_{d}$ & 1.320 & Drum material mix volume $\left(\mathrm{m}^{3}\right)$ \\
\hline$Q_{d, i, \text { med }} / Q_{d, i}$ & 0.788 & $\begin{array}{l}\text { Ratio of the volumetric flow rate of the } \\
\text { magnetite medium in the feed mix to } \\
\text { overall volumetric flow rate of the feed mix }\end{array}$ \\
\hline $\begin{array}{l}Q_{d, i, a s h} /\left(Q_{d, i}-\right. \\
\left.Q_{d, i, m e d}\right)\end{array}$ & 0.111 & $\begin{array}{l}\text { Ratio of the volumetric flow rate in the feed } \\
\text { ash to the feed ore }\end{array}$ \\
\hline$\Delta_{\rho_{d, \text { med }}}$ & 1.00 & $\begin{array}{l}\text { Difference between feed medium density } \\
\text { with float or sink medium density }\left(\mathrm{kg} / \mathrm{m}^{3}\right)\end{array}$ \\
\hline
\end{tabular}

\section{Simulation results}

This section describes the simulation results for the DMD dynamic model. Initially the throughput of the DMD process is simulated and verified. Based on the verified throughput model, the partition curve is generated by reducing the dynamic model to a steady-state model. The partition curve result is then used in association with the equations 2 and 5 to estimate the input-output data for the grade simulation.

The following steps were used to obtain the calculated results:

- Step 1: Fit the DMD dynamic model to the measured mass flow rate input-output data $\left(W_{d, i}, W_{d, f}\right.$ and $\left.W_{d, s}\right)$.

- Step 2: Fit the partition factor function (equation 2) to a steady-state model derived from the dynamic model in step 1.

- Step 3: Calculate the float ash content $\left(x_{d, f, a s h}\right)$ using equation 4.

- Step 4: Calculate the feed ash content $\left(x_{d, i, a s h}\right)$ using equation 5 with the results from steps 2 and 3.

- Step 5: Calculate the sink ash content $\left(x_{d, s, a s h}\right)$ using the conservation of mass of components.

Table 5 indicates which input-output variables are either measured or calculated.

\subsection{Throughput}

The input data for the drum separator simulation are shown in Figure 7. The feed rate of the drum feed material is not controlled as it is dependant on an upstream crushing and screening plant. The density of the drum medium is controlled and is stepped from about $1600 \mathrm{~kg} / \mathrm{m}^{3}$ to $1640 \mathrm{~kg} / \mathrm{m}^{3}$ as shown in Figure 7 .

The feed mix $\left(W_{d, i}\right)$ is a combination of the feed ore $\left(W_{d, i, \text { ore }}\right)$ and the feed medium $\left(W_{d, i, \text { med }}=\rho_{d, i, \text { med }} Q_{d, i, m e d}\right)$. This feed mix is modelled using the dynamic model of a mixing box developed by Meyer and Craig (2010), and is not shown here. 
Table 5: Input-output variable source definitions

\begin{tabular}{ll}
\hline Variable & Data source \\
\hline$W_{d, i}$ & Measured \\
$x_{d, i, a s h}$ & Calculated using equation 5 together with equations 2 and 4 \\
$\rho_{d, i, m e d}$ & Measured \\
$W_{d, f}$ & Measured \\
$x_{d, f, a s h}$ & Calculated using equation 4 \\
$W_{d, s}$ & Measured \\
$x_{d, s, a s h}$ & Calculated using the conservation of mass of components \\
\hline
\end{tabular}

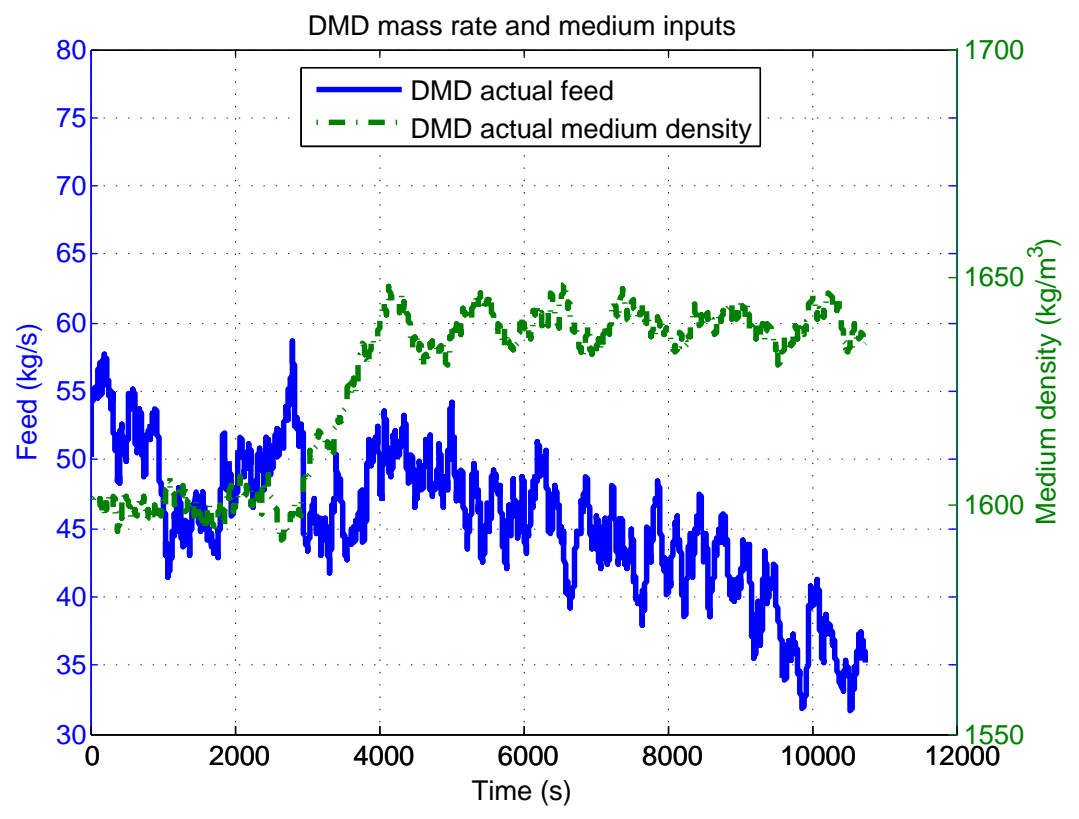

Figure 7: Input data for throughput simulation. 
Figure 8 illustrates the comparison between the measured drum separator floats product mass rate and the dynamic model predicted output.

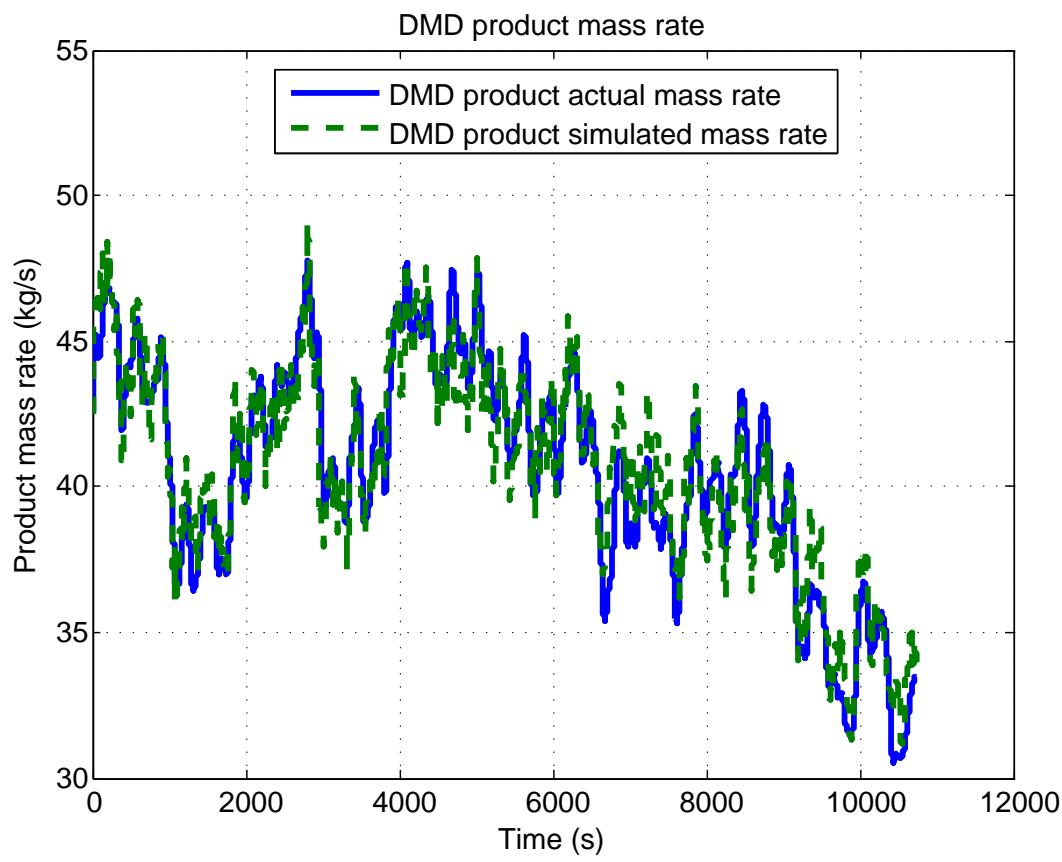

Figure 8: Drum separator floats product.

Figure 9 illustrates the comparison between the measured drum separator sinks discard mass rate and the dynamic model predicted output.

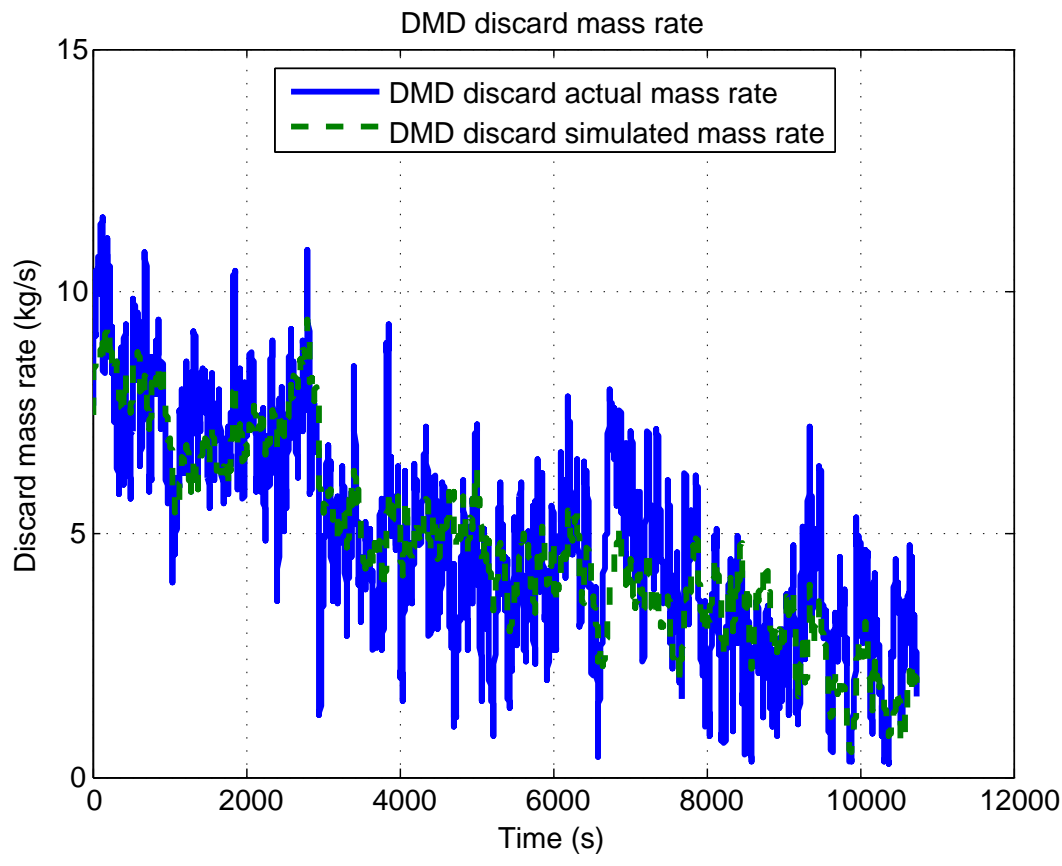

Figure 9: Drum separator sinks discard. 
The model estimates for the floats product and sinks discard as shown in Figures 8 and 9 respectively, are considered to be adequate for process control studies as they are qualitatively accurate.

\subsection{Partition curve}

This section details a process steady-state model derived from the dynamic model described in Section 3. The derivation is based on Meyer and Craig (2011) and Meyer and Craig (2014). A model fit was performed using the partition curve from equation 1 . The predicted mass distributions to float and sink products at different particle densities in the feed $\left(\rho_{d, i, \text { ore }}\right)$ are obtained by simulating the partition factor at different medium densities $\left(\rho_{d, i, m e d}\right)$. By starting with a finite amount of mass in the feed and simulating the separation at steady-state at a high density, the resulting mass in the float can be used as the feed for the next steady-state simulation. With decreasing medium density iterations, the resulting partition factors can be obtained. By fitting equation 1 to the simulated observations the partition curve in Figure 10 was generated.

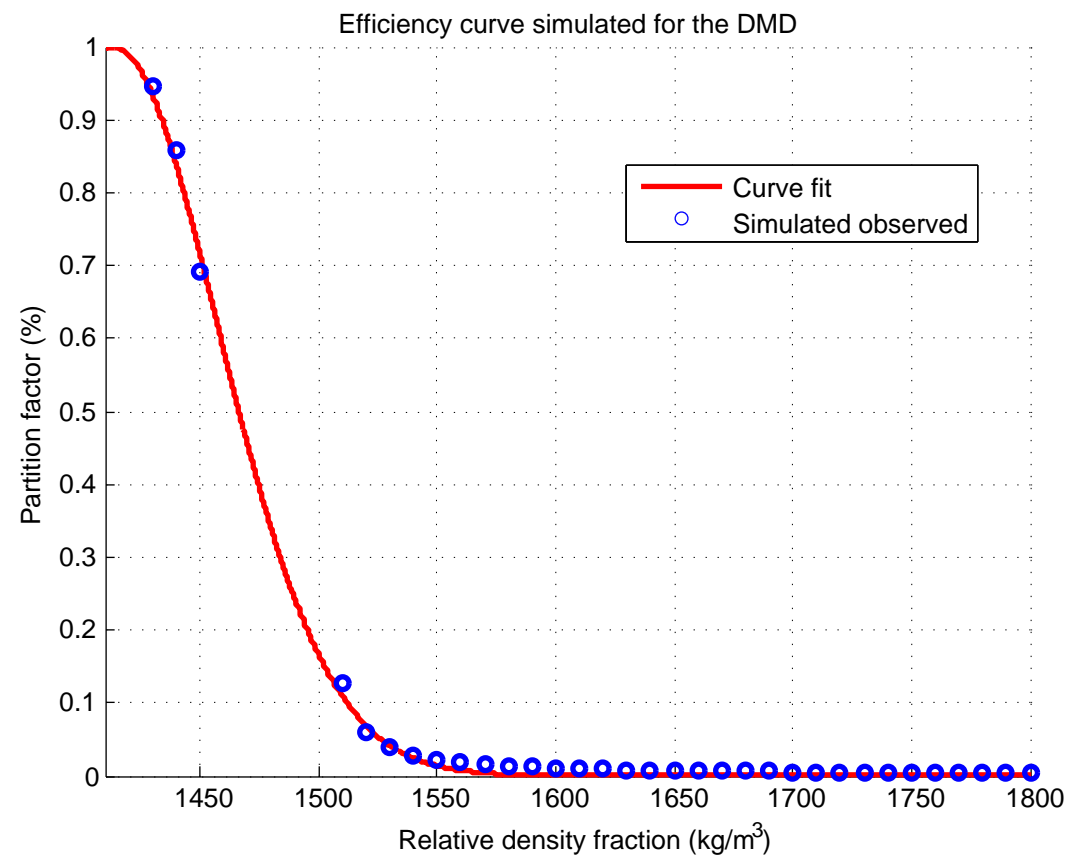

Figure 10: Simulated efficiency curve for the drum separator using the steady-state model derived from the dynamic drum model.

Table 6 shows a summary of the parameters for the efficiency curve fit. This simulation indicates that a dynamic drum separator model can be reduced to a realistic steady-state model from which a partition curve can be generated.

\begin{tabular}{ll}
\multicolumn{2}{l}{ Table 6: Partition curve efficiency model parameters. } \\
\hline $\begin{array}{l}\text { Efficiency } \\
\text { parameter }\end{array}$ & $\begin{array}{l}\text { Efficiency curve fit } \\
\text { parameter results }\end{array}$ \\
\hline \hline$p_{1}$ & 0.594 \\
$p_{2}$ & 498.60 \\
$p_{3}$ & $5.968 \mathrm{e}+03$ \\
\hline
\end{tabular}

Using equation 3 the EPM is determined as $0.021 \mathrm{SG}$ based on the partition curve in Figure 10. It was indicated by the process development engineer responsible for the production facility where the Wemco drum separator model has been applied that the separation efficiency results align very well with the actual Wemco drum separator efficiency (Steyn, 2014). An actual efficiency curve of the Wemco drum separator was not available. 


\subsection{Grade}

Since no online measurement was available to measure the product and discard grade, the method of reconstituting the feed ash component percentage and estimation of the product ash component percentage explained in Section 2 was used. The previous efficiency curve results combined with equations 2 and 5 were used to estimate the input-output data for the grade simulation.

As a result the input data for the drum separator grade simulation are shown in Figure 11. The feed ash percentage of the drum feed material is not controlled as it is dependant on an upstream mining and blending process. The density of the drum medium is also shown as an input similar to that shown in Figure 7.

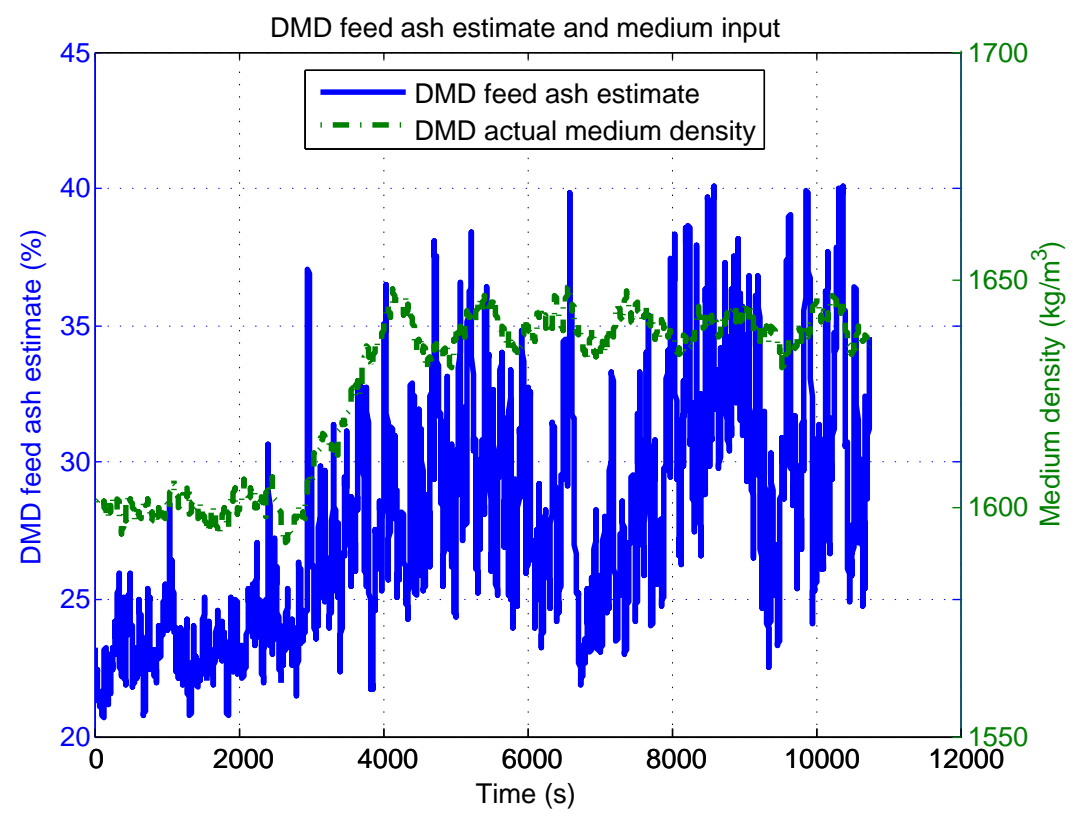

Figure 11: Input data for grade simulation.

Figure 12 illustrates the comparison between the measured drum separator floats product ash percentage and the dynamic model predicted output. A detailed view of the floats product ash percentage comparison is given in Figure 13 from time 6000 seconds to 8000 seconds.

Figure 14 illustrates the comparison between the measured drum separator sinks discard ash percentage and the dynamic model predicted output. A detailed view of the sinks discard ash percentage comparison is given in Figure 15 from time 2000 seconds to 4000 seconds.

The model estimates for the floats product ash percentage and sinks discard ash percentage as shown in Figures 12 and 14 respectively, are considered to be adequate for process control studies as they are qualitatively accurate. 


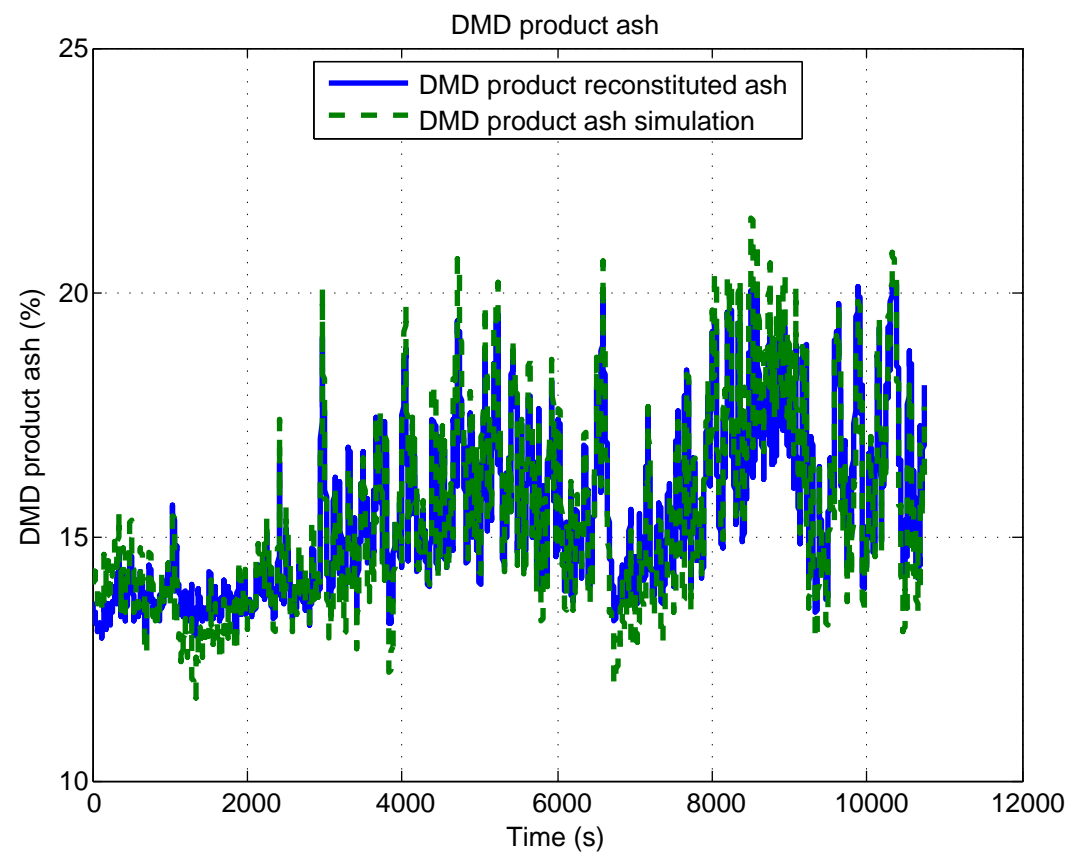

Figure 12: Drum separator floats product ash percentage simulation.

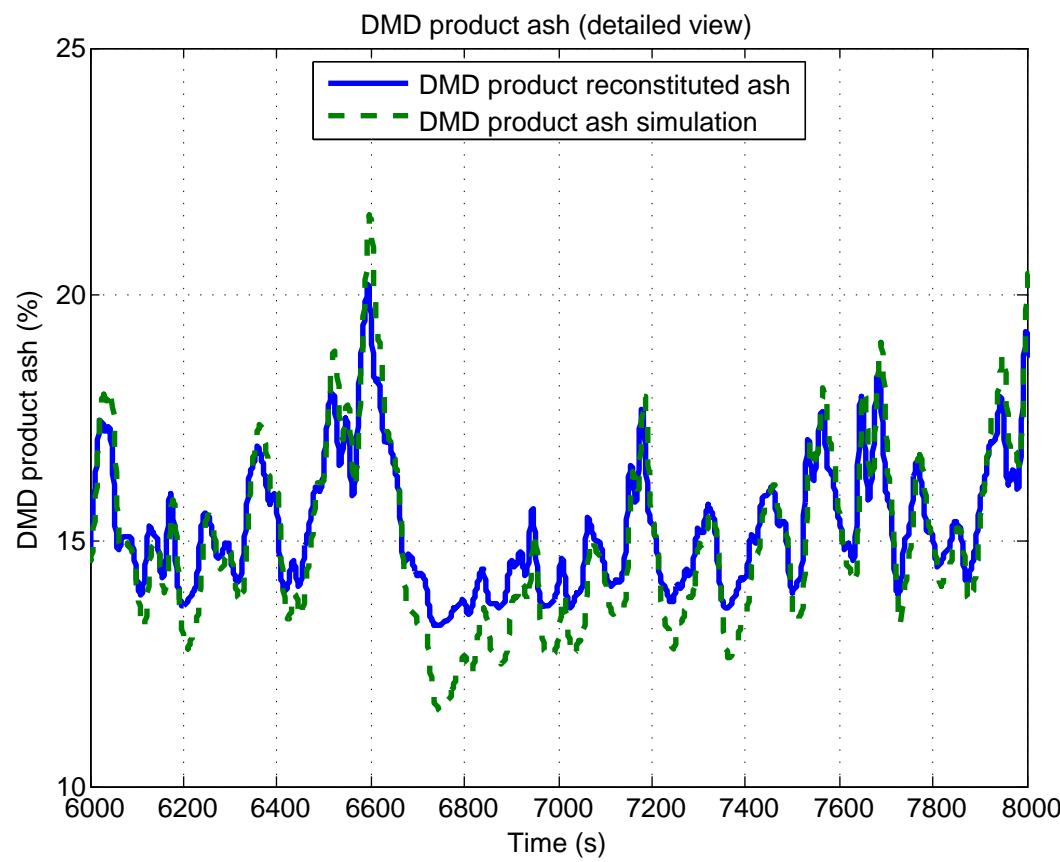

Figure 13: Drum separator floats product ash percentage simulation (detailed view). 


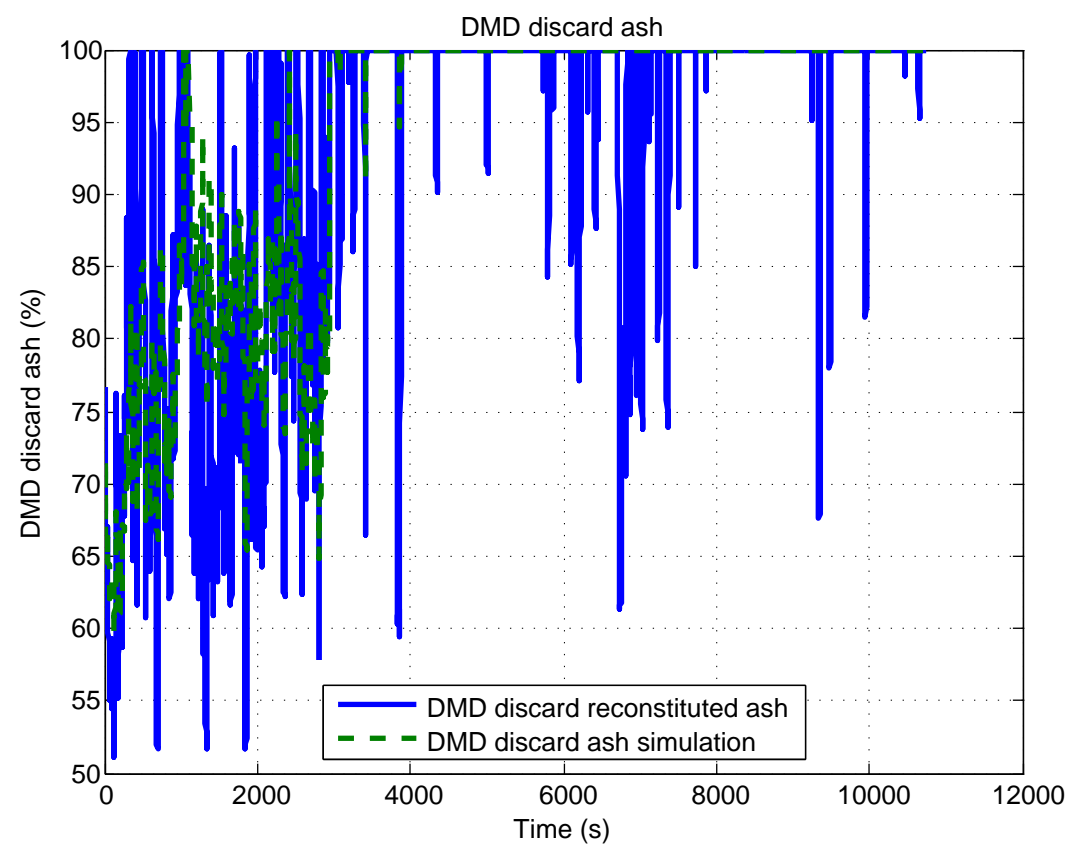

Figure 14: Drum separator sinks discard ash percentage simulation.

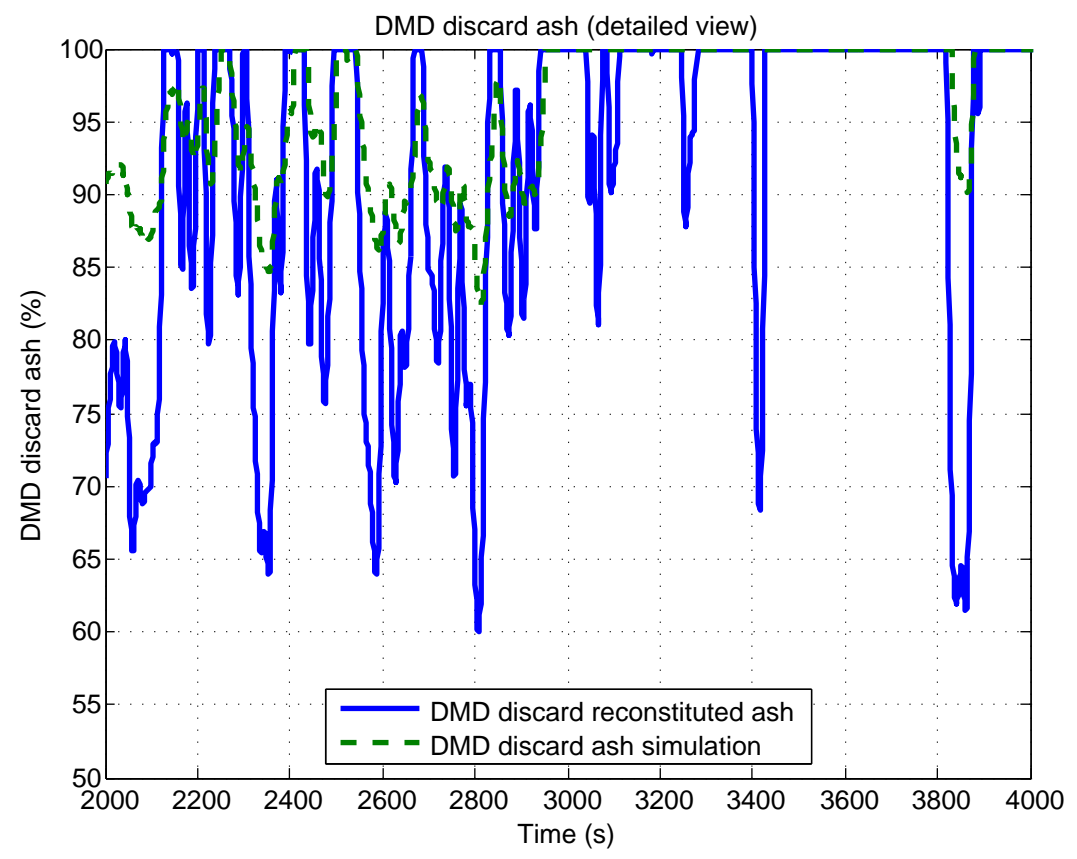

Figure 15: Drum separator sinks discard ash percentage simulation (detailed view). 


\section{Discussions and conclusion}

This paper shows that a newly developed dense medium drum dynamic model can provide relatively accurate predictions of drum dynamics. This development is based on the dense medium cyclone model of Meyer and Craig (2010). It also illustrates that partitioning behaviour similar to a dense medium cyclone is applicable to the drum separator model. The validation of the dynamic model is further confirmed by the metallurgical steady-state efficiency measures (Table 7).

Table 7: Partition curve efficiency results summary.

\begin{tabular}{ll}
\hline Efficiency parameter & Simulated steady-state model results \\
\hline \hline$\rho_{50}$ & $1.470 \mathrm{e}+03 \mathrm{~kg} / \mathrm{m}^{3}$ \\
$\mathrm{EPM}$ & $0.021 \mathrm{SG}$ \\
\hline \hline
\end{tabular}

The dynamic model goodness of fit (Ljung, 2005) and correlation between the measured outputs and simulated outputs is given in Table 8 .

\begin{tabular}{ccc} 
Table 8: Dynamic DMD model performance results summary \\
\hline Output & Fit (\%) & Correlation \\
\hline \hline Product throughput & 69.04 & 0.95 \\
Discard throughput & 43.45 & 0.83 \\
Product grade (ash) & 66.40 & 0.96 \\
Discard grade (ash) & 56.26 & 0.57 \\
\hline \hline
\end{tabular}

This model performance is considered adequate for process control purposes as responses are in general qualitatively accurate for the Wemco drum separator. The only correlation that is relatively low is for the discard grade prediction. The correlation for all other outputs are good. The lower correlation on the discard ash could be due to insufficient measured plant data. The discard stream was not measured directly through a belt scale as this stream was combined with discard from other DMC plant discards. The proportionality constants were estimated to very small numbers for the rates of change in float and sink density. This small change in rate of change in density provides further confidence in the DMD dynamic model as the unit is operating much closer to steady-state than a DMC.

The DMD dynamic model grade simulation results in Subsection 4.3 are being compared to calculated input-output data shown in Table 5. What this means is that the calculated input-output grade data are based on measured yield (i.e. measured mass flow rates), a simulated partition curve and the measured washability of the coal. The dynamic DMD model (specifically grade dynamics) with unknown parameters are essentially fitted to the calculated input-output grade data. There is no correspondence between the mathematical formulation of the dynamic model with unknown parameters and the calculated input-output data. This implies that the grade dynamics of the DMD model are able to represent the calculated input-output grade data and confirms the mathematical derivation of the dynamic model. However, it is still recommended that further work is performed where measured online ash contents is used instead of the calculated input-output grade data to further verify the dynamics of the mathematical model.

In summary, this paper shows the following:

- a dynamic model of a Wemco dense medium drum separator based on first principles.

- model parameters determined from actual plant data from a Wemco drum.

- a validated dynamic model using additional plant data with a comparison to a steady-state process model.

- the use of coal washability to estimate product and feed grade for simulation. 


\section{References}

Baguley, P.J., Napier-Munn, T.J., 1996. Mathematical model of the dense medium drum. Trans. Inst. Min. Met. (Section C) 105, C1-C8.

Bowen, R.M., Jowett, A., 1986. Coal cleaning calculations based on alternatives to standard washability curves. Fuel 65, 28-33.

Concha, F., Almendra, E., 1979. Settling velocities of particulate systems, 1. Settling velocities of individual spherical particles. International Journal of Mineral Processing 5, 349-367.

England, T., Hand, P.E., Michael, D.C., Falcon, L.M., Yell, A.D., 2002. Coal Preparation in South Africa. 4 ed., Natal Witness Commercial Printers, Pietermaritzburg, South Africa.

Faure, K., Willis, J.P., Claris Dreyer, J., 1996. The Grootegeluk formation in the Waterberg coalfield, South Africa: Facies, palaeoenvironment and thermal historyevidence from organic and clastic matter. International journal of coal geology 29, 147-186.

Halliday, D., Resnick, R., Walker, J., 2001. Fundamentals of physics. 6 ed., John Wiley \& Sons, Inc., United States of America.

Hayes, P., 2003. Process principles in minerals and materials production. 3 ed., Hayes Publishers, Brisbane, Australia.

King, R.P., 1999. Practical optimization strategies for coal-washing plants. International Journal of Coal Preparation and Utilization 20 , 13-34.

Ljung, L., 1987. System Identification: Theory for the User. 1 ed., Prentice-Hall, Inc, Englewood Cliffs, NJ.

Ljung, L., 2005. System identification toolbox user's guide. 7 ed., The MathWorks, Inc, Natick, MA, USA.

Mayer, F., 1950. Die mittelwertkurve, eine neue verwachsungskurve. Glückauf , 498-509.

Meyer, E.J., Craig, I.K., 2010. The development of dynamic models for a dense medium separation circuit in coal beneficiation. Minerals Engineering 23, 791-805.

Meyer, E.J., Craig, I.K., 2011. Development of a steady-state partition curve from a dense medium cyclone dynamic model in coal beneficiation, in: Proceedings of the 18th IFAC World Congress, Milano, Italy, IFAC. IFAC. pp. 10523-10528. doi:10.3182/20110828-6-IT-1002.02846.

Meyer, E.J., Craig, I.K., 2014. Coal dense medium separation dynamic and steady-state modelling for process control. Minerals Engineering 65, 98-108.

Napier-Munn, T.J., 1991. Modelling and simulating dense medium separation processes - a progress report. Minerals Engineering 4, 329-346.

Reinhardt, K., 1911. Characteristik der Feinkohlen und ihre aufbeteitung mit Rucksicht auf das grösste Ausbringen. Glückauf 47, $221-228$.

Scott, I.A., Lyman, G.J., 1987. Metallurgical evaluation of iron ore drum separators using density tracers, in: Proceeding of the Australian Institute of Mining and Metallurgy, February, 1987, pp. 49-56.

Stephanopoulos, G., 1984. Chemical process control: An introduction to theory and practice. 1 ed., Prentice-Hall, Inc., Englewood Cliffs, New Jersey.

Steyn, H., 2014. Wemco drum partition curve verification. Private communication.

Terra, A., 1938. Theory of washing coal. Revue Industrie Minerale 425, 383.

Wilkes, K.D., 2006. The practical application of the Wemco HMS Drum Separator in the mining and metals recycling industries, in: Proceedings of the SAIMM Present Status and Future for DMS Gravity Concentration in the South African Mining Industry Conference, 18-20 July, 2006, SAIMM. pp. 179-190.

Wills, B.A., Napier-Munn, T., 2006. Wills' Mineral Processing Technology: An introduction to the practical aspects of ore treatment and mineral recovery. 7 ed., Elsevier Ltd. 